\title{
Liberación, desideologización, y derechos humanos, categorías para una apología de la autonomía de las mujeres
}

Mirian Irene Meléndez Cartagena

Docente de Filosofía

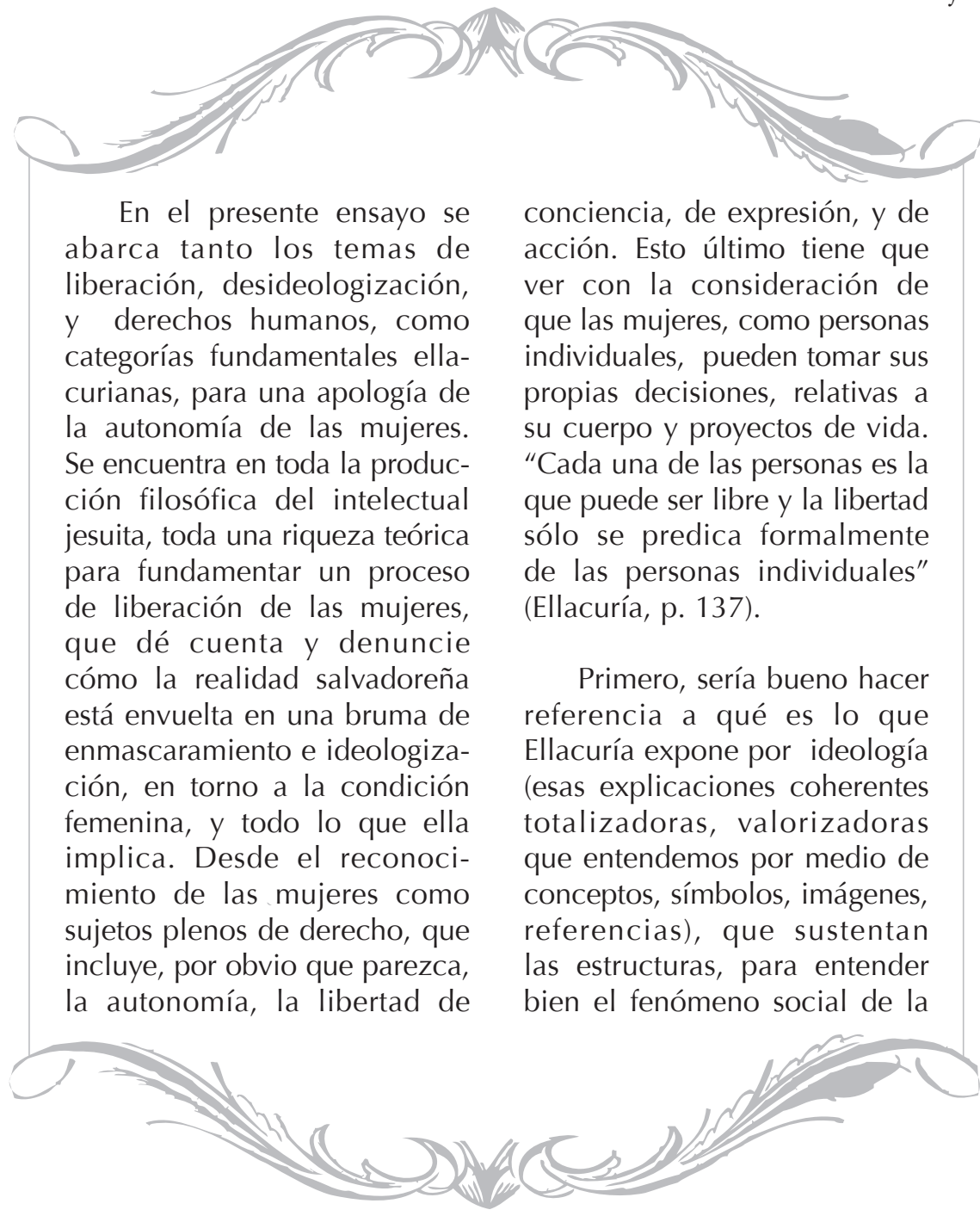


ideologización, que a través de las estructuras jurídicas, políticas, y demás instituciones sociales, frena las potencialidades y humanización de los sujetos mujeres.

Para Ellacuría, hay que llegar siempre al fondo de las cuestiones y preguntarse por qué el ser humano necesita explicaciones y justificaciones teóricas, y por qué en esas explicaciones y justificaciones, no basta con que se hagan desde la apariencia de verdad y de bien. En el texto "El lugar de la teoría", hay una radicalidad ética y una preocupación que no sólo es teórica, sino también moral, por entender muy bien y advertir como la desideologización deforma y presenta ante la opinión pública como verdadero y justo, lo que realmente es falso e injusto, propiciando un orden de caos moral, violencia, opresión, e injusticia. En este escrito, la intención es presentar el desajuste que se da entre el derecho proclamado, el derecho a la vida desde la concepción, y la realidad compleja de los cuerpos de las mujeres.

Pero, ¿Qué es lo que se pierde en la ideologización?, ¿Cuánto se ha deformado?, ¿Cuánto se ha callado? En materia jurídica y de derechos humanos, cuántas mujeres han sido procesadas judicialmente, por el sólo hecho de ser mujeres, con complicaciones en sus embarazos, y en condiciones de pobreza. En el país, desde 1997 se dio un retroceso en materia jurídica (iniciativa propuesta por grupos conservadores religiosos y políticos) penalizando todo tipo de aborto (terapéutico, ético y eugenésico), constituyendo esto una atentado hacia las libertades, salud, e integridad física, y moral, de las mujeres salvadoreñas.

En el libro, La lucha por la justicia, Selección de textos de I. Ellacuría, de Juan Antonio Senent, se encuentra lo siguiente: "Los derechos humanos son momentos ideológicos de una determinada praxis, que pueden convertirse en momentos ideologizados cuando ocultan o protegen intereses y privilegios minoritarios" (Ellacuría, p.364). Estos intereses minoritarios pueden ser de índole política, y se sabe, gracias a los feminismos, que los discursos, iniciativas y movilización por la liberación de las mujeres, ya sean en materia de educación, participación política y ciudadana, y sexualidad, siempre han sido objeto de impugnación por parte de sectores conservadores y por los que se llaman así mismos "progresistas" (políticos y religiosos) de la sociedad, donde prevalece más, el interés por la consecución en el poder, y no la justicia, igualdad, y el bienestar común de la población.

En nuestro país se criminaliza el ser mujer, no se respeta la autonomía y libertad de decidir de las mujeres, se penaliza todo tipo de aborto, constituyéndose esto, 
dicho sin ambages, en un problema grave de liberación y de derechos humanos. El Estado salvadoreño (uno de los nueve países en todo el mundo que prohíbe la interrupción del embarazo en todos los supuestos, incluso cuando la vida de la mujer embarazada está en riesgo, o cuando el embarazo es fruto de una violación), ha sido señalado por organismos internacionales, como un estado que atenta impunemente contra derechos sexuales y reproductivos, que también son considerados derechos humanos. "Los derechos humanos son prescripciones éticas, obligantes en conciencia y que humanizan o deshumanizan a individuos, grupos o pueblos, según sea la habitud y la actitud respecto de ellos, así como su cumplimiento o incumplimiento actuales". (Ellacuría, p.364).
Desde el pensamiento ellacuriano, los derechos humanos son definidos como "una necesidad de la convivencia social y política, son una necesidad socio-biológica y político-biológica, sin la que se hace inviable la especie y el modo social y político, en que la especie humana debe desenvolverse" (Ellacuría, p. 363). En relación a lo anterior, y para que no quede duda sobre la incompetencia en la que incurre el estado salvadoreño, Amnistía Internacional, a través de su secretario, Salil Shetty, ha hecho un Ilamamiento al Estado salvadoreño para que proceda a la "liberación inmediata y sin condiciones" de todas las mujeres y jóvenes encarceladas por aborto en este país y derogue las leyes que lo penalizan, y ha dicho lo siguiente:

"La inacción del gobierno salvadoreño a la hora de abordar la discriminación contra las mujeres limita gravemente las vidas de las mujeres y las niñas. Al negarse a resolver adecuadamente las infranqueables barreras existentes para acceder a métodos anticonceptivos y a una verdadera educación sexual, condenan a generaciones de mujeres jóvenes a un futuro determinado por la desigualdad, la discriminación, la limitación de sus opciones y la restricción de sus libertades".

"Ni en lo personal ni en lo histórico puede hablarse de libertad si no se dan las condiciones materiales y objetivas que limitan (impiden) la libertad y, a su vez, se necesita un conjunto de condiciones para que la libertad pueda desarrollarse" (Ellacuría, p. 137).
Dichas condiciones no están dadas y es por esto que es urgente fundamentar un proceso de liberación que sirva de base para la movilización de distintos sectores y actores de la sociedad civil, no sólo de las mujeres, para la transformación de la sociedad, donde prevalezcan y 
se reconozcan y se hagan efectivos unos mínimos éticos. Según Adela Cortina, dichos preceptos mínimos son la igualdad y la solidaridad, sin los cuales la sociedad no puede y no debe funcionar, ella hace énfasis en que para que exista la igualdad real y efectiva es necesario el reconocimiento de la autonomía de los sujetos.

Salil Shetty, ha señalado también que "las cosas no cambiarán mañana", pero confía en que Amnistía Internacional tiene la capacidad para influir y hacer presión, para que en el futuro, el Estado salvadoreño derogue la prohibición absoluta del aborto y respete sus compromisos internacionales en relación a los Derechos Humanos. Planteado esto, sólo cabe deducir que el mismo Estado salvadoreño incurre en la ilegalidad e incumplimiento, suscribiendo tratados internaciones de derechos humanos, mientras en la práxis los anula, retrasando a su vez, el proceso de democratización y construcción de un Estado pleno de derecho. Siendo un Estado ideologizado (patriarcalmente) y enmascarado de intereses, y que, siguiendo a Ellacuría, persiste impunemente en la nada de lo ideologizado, revirtiéndose esto, para las mujeres, en un abismo jurídico torturante $y$ que maltrata.

Desideologizar no es algo que tenga que ver con un ente encargado de la transparencia, o con un tribunal de probidad o ética gubernamental, o con la apelación a un organismo internacional, sino que es algo que tiene que ver con la razón, y la actividad por excelencia de la razón, es el filosofar, y dicha actividad será efectiva sólo desde la criticidad y fundamentalidad, ya con estos dos elementos nos podemos enfrentar a la nada de lo ideologizado. Ellacuría, asimismo, dentro de esta misma línea menciona que la nada trae consigo una acción negadora, o sea una negatividad crítica. La negatividad es el punto de partida de la crítica y es su motor, y se puede resaltar que dicha negatividad crítica es la que puede situarnos más allá de la realidad sin fundamento (éste es el ámbito de lo ideologizado, y donde hay ideologización, seguramente hay injusticia).

Lo anterior, a mi modo de ver, sugiere que se puede salir de la ilegalidad, injusticia, y del sinsentido, ya que son estos mismos elementos los contienen negatividad en sí, y una contradicción latente, que hace que en el sujeto surja una posición contraria a lo que se está viviendo. También se puede plantear que los sujetos y los colectivos se han afirmado "acríticamente" en la nada de lo ideologizado, y contra esto es que, en mi opinión, surge el método de historización ellacuriano, como principio, a su vez, de desideologización, que consiste en: 
“a) La verificación práxica de la verdad-falsedad, justiciainjusticia, ajuste-desajuste que se da del derecho proclamado; b) en la constatación de si el derecho proclamado sirve para la seguridad de unos pocos y deja de ser efectivo para los más; c) en el examen de las condiciones reales, sin las cuales no tienen posibilidad de realidad los propósitos intencionales; d) en la desideologización de los planteamientos idealistas, que en vez de animar los cambios sustanciales, exigibles para el cumplimiento efectivo del derecho y no sólo para la afirmación de su posibilidad o desiderabilidad, se convierten en obstáculo de los mismos, e) en la introducción de la dimensión tiempo para poder cuantificar y verificar cuándo las proclamaciones ideales se pueden convertir en realidades o alcanzar, al menos, cierto grado aceptable de realización". (Ellacuría, p. 366).

De forma sucinta y directa se puede aplicar dicha metodología al problema del no reconocimiento de la autonomía y libertad de las mujeres (aunque claramente no haya sido concebida para ello). En relación al literal a) si se verifica la inconsistencia de la proclamación del derecho a la vida desde la concepción, restringiendo la libertad de las mujeres y atentando contra su salud y vida, siendo ya éstas sujetos plenos de derecho; b) el derecho proclamado (derecho a la vida desde la concepción) no es efectivo para la mayoría, por la complejidad de los cuerpos; c) si el propósito es defender la vida de los no nacidos, se dejan fuera las condiciones reales, que derivan de la complejidad de los cuerpos de las mujeres y situación socioeconómica, intereses, y proyecto de vida de las mismas; d) desideologización de los planteamientos idealistas (derecho a la vida desde la concepción) esto no anima cambios sustanciales, sino que se convierte en obstáculo para el derecho mismo a la vida, el cual la mujer sí puede exigir porque ya es un sujeto pleno de derechos, con conciencia e intereses; e) este último elemento, la introducción del factor tiempo, a mi criterio, puede servir más para verificar y advertir el peligro, de que, los derechos en su teoría y práxis, adquieran la forma de una normatividad absoluta y abstracta, independiente de toda circunstancia histórica y por ende, aparezcan a la ciudadanía, vacíos de contenido.

Si bien es cierto que Ellacuría nunca escribió desde la perspectiva de género, sí escribió siempre desde un enfoque filosófico, crítico, humanista, antropológico, ético y por todo ello, liberador, coincidiendo, en este sentido, con los feminismos, si se les considera así, en todas estas vertientes, asimismo, como un tipo 
de planteamiento multidisciplinario e interdisciplinario, que quiere revelar las verdades sobre el patriarcado y el capitalismo, con criticidad y fundamentalidad, elementos que permiten realizar una tarea desideologizante, desde el filosofar.

Patriarcado y capitalismo, dos mounstros contemporáneos, uno de ellos, el segundo, ha sido descrito y denunciado en múltiples escritos por Ellacuría y el otro se ha quedado sin historizar, entendiendo por esto, el mostrar que van dando de sí los conceptos, en una determinada realidad, el mismo Ellacuría ha dejado las pautas para que las nuevas generaciones se ocupen de ello. Según él: "las ideologías dominantes viven de una falacia fundamental, la de operar como conceptos reales e históricos, como valores efectivos y operantes, como pautas de acción eficaces (...) como abstractos y universales son admitidos por todos, aprovechándose de ello, se subsumen realidades que, en su efectividad, histórica, son la negación de lo que dicen ser" (Ellacuría, p.239). Para historizar el concepto patriarcado basta con consultar artículos como: "El lugar de la teoría", "La función liberadora de la filosofía", "Historización de los derechos humanos desde los pueblos oprimidos y las mayorías populares", "La historización del concepto de propiedad como principio de desideologización" y otros.

Como se menciona en el artículo, "El lugar de la teoría", la situación o el lugar desde el que parte el filosofar es en cada caso "objeto de un acto de elección reflexiva" por parte de cada pensador, lo ha sido en el pasado, y lo es ahora para quienes eligen determinada "trinchera" de pensamiento, en mi caso, la reflexión filosófica feminista.

Los sujetos optan por aquel lugar que muestra ser el adecuado punto de partida para la labor filosófica, un lugar que nos pueda dar una retribución de verdad, porque la verdad es útil, y lo que no es verdad, es inútil, y en los respectivos ámbitos (filosofía y derechos humanos) desde los que se está abordando la cuestión de la restricción de libertad y autonomía de las mujeres, se verifica que dicha situación puede calificarse de tortura y maltrato, deuda con las víctimas, y deshumanización.

"Las constituciones democráticas pueden proponer toda suerte de libertades formales, pero de ellas sólo se pueden aprovechar quienes tengan las condiciones reales para hacerlas realidad. De ahí que una lucha auténtica por la libertad exige la transformación (revolucionaria o no) de aquellas condiciones reales que impiden o dificultan al máximo la libertad socio-política y económica de la mayor 
parte de un pueblo. La liberación de las estructuras injustas y la creación de nuevas estructuras, fomentadoras de la dignidad y de la libertad, se constituyen, por lo tanto, en camino esencial de la libertad, de la libertad para los individuos dentro de su contexto nacional y de libertad para los pueblos dentro de su contexto internacional". (Ellacuría, p. 137).

Los derechos humanos aun siendo ambiguos en su configuración puede ser camino para opciones éticas y posibilidades de transformación utópica, esto último, sería para las mujeres el lugar ideal, posible y exigible: sin coerción y condena arbitraria, sin suicidios de jóvenes y adolescentes (enfrentando la compleja condición de ser mujer), sin miedos, un lugar de libertad, oportunidad, de plenificación y de humanización. Según H. Samour, en su artículo "Filosofía y liberación", "Ellacuría exigirá del filósofo fidelidad a la propia vocación filosófica y a sí mismo, rigurosidad y profundidad teóricas, distancia crítica frente a cualquier forma de poder y de praxis, y compromiso vital, existencial, con la búsqueda de la verdad y su realización práxica en la propia realidad histórica".

La distancia, en este caso, es hacia el sistema patriarcal, capitalista, conservador, y opresor. En el seminario virtual sobre el pensamiento social y político ellacuriano, se ha estudiado la configuración de ese sistema, no en su veta patriarcal sino, del capital, pero ha sido por inspiración misma de la radicalidad del propio intelectual, la que me ha movido a hacer una defensa de la liberación y autonomía de las mujeres, aunque en la coyuntura actual se considere ideologizadamente y temerariamente, para ciertos sectores, una «apología del delito».

\section{Referencias bibliográficas}

Libro:

os Juan Antonio Senent de Frutos. (2012). La lucha por la justicia, selección de textos de I. Ellacuría. Bilbao: Universidad de Deusto.

Artículo:

os Samour Canán, H. "Filosofía y Liberación" (2001) Recuperado de: http://www.uca.edu.sv/filosofia/admin/files/1201492632.pdf 